\title{
Comparison of two types of the triple incision technique in the treatment of patients with locally advanced vulvar cancer
}

\author{
Ying $\mathrm{Ma}^{1,3^{*}}$, Wei-feng Liang ${ }^{2,3^{*}}$, Chang-hao $\mathrm{Liu}^{3}$, Zhong-qiu $\operatorname{Lin}^{3}$, Miao-fang Wu ${ }^{\circledR 凶}$ and Jing $\mathrm{Li}^{3 凶}$ \\ 1. Department of Obstetrics and Gynecology, the First Affiliated Hospital of Dalian Medical university, Dalian, 116011, People's Republic of China \\ 2. Department of Gynecology and Obstetrics, Qilu Hospital (Qingdao), Cheeloo College of Medicine, Shandong University, Qingdao, 266035, People's \\ Republic of China. \\ 3. Department of Gynecologic Oncology, Sun Yat-sen Memorial Hospital, Sun Yat-sen University, Guangzhou, 510120, People's Republic of China. \\ *These authors contributed equally to this work.
}

$\square$ Corresponding authors: Jing Li, MD, PhD, Department of Gynecologic Oncology, Sun Yat-sen Memorial Hospital, Sun Yat-sen University, 33 Yingfeng Road, Guangzhou 510000, People's Republic of China, Tel: +86 020 34078521, Fax: +86 020 34071260, E-mail: lijing228@mail.sysu.edu.cn; Miao-fang Wu, MD, Department of Gynecologic Oncology, Sun Yat-sen Memorial Hospital, Sun Yat-sen University, 33 Yingfeng Road, Guangzhou 510120, People's Republic of China, Tel: +86 020 34071260, Fax: +86 020 81330211, E-mail: miaofang_wu@outlook.com.

(C) The author(s). This is an open access article distributed under the terms of the Creative Commons Attribution License (https://creativecommons.org/licenses/by/4.0/). See http://ivyspring.com/terms for full terms and conditions.

Received: 2020.06.22; Accepted: 2020.09.01; Published: 2020.09.16

\begin{abstract}
Objective: In 2012, we proposed and described a modified triple incision technique (MTIT) for vulvar cancer patients with locally advanced disease. The MTIT has undergone a series of modifications, and a modified MTIT (M-MTIT) has been developed. The purpose of this study was to introduce the M-MTIT and compare it with the MTIT.

Study design: This was a retrospective cohort study. Fifty-seven vulvar cancer patients with clinical stage T2 $(\geq 4 \mathrm{~cm})$ or T3 disease were included. Of these patients, 28 underwent the MTIT and 29 underwent the M-MTIT. Data on surgery-related complications and survival outcomes were compared.

Results: Patients who were treated with the M-MTIT developed significantly less surgery-related morbidities than patients treated with the MTIT $(24.1 \%$ vs. $60.7 \%, P=0.005)$. Wound breakdown was the most common complication in our cohort, which occurred less frequently in the M-MTIT group than in the MTIT group $(10.3 \%$ vs. $35.7 \%, P=0.022)$. Multivariate logistic regression analysis identified the M-MTIT as an independent predictor of a reduced risk of wound breakdown. The incidence of other complications, including lymphedema, wound infection and cellulitis, was lower in the M-MTIT group than in the MTIT group; however, the differences did not reach statistical significance. The median follow-up time of this study was 33 months. Kaplan-Meier survival graphs did not show significant differences in recurrence-free survival or overall survival between the two groups.

Conclusions: The M-MTIT correlates with lower morbidity rates than the MTIT and does not compromise oncological safety. The M-MTIT can be considered a safe and feasible option for vulvar cancer patients with locally advanced disease.
\end{abstract}

Key words: vulvar cancer, triple-incision technique, complication, survival

\section{Introduction}

For patients with vulvar cancer, radical excision of the tumor with inguinofemoral lymph node dissection (ILND) is a major extirpative procedure [1-3]. Although the efficacy of this treatment is good, morbidity following surgery can be substantial. To reduce complication rates, considerable efforts have been made in recent years. Introduction of the sentinel-node procedure was one of the most promising advances and has been validated as a safe alternative to ILND for patients with early-stage disease (T1 or T2 $<4 \mathrm{~cm}$ ) [4,5]. However, for patients with more advanced disease, en bloc radical 
vulvectomy with bilateral ILND remains the standard surgical procedure [1, 2]. In 2012, we reported a modified triple incision technique (MTIT) and proposed it for vulvar cancer patients with locally advanced disease [6]. While data from the study suggested that the MTIT could be safe, feasible and tolerable, there is still room for improvement. Since 2009, the original MTIT has undergone several modifications. The aims of the present study were (1) to evaluate whether the modified MTIT (M-MTIT) is superior to the MTIT in terms of postoperative morbidity and (2) to assess whether the M-MTIT is equal to the MTIT regarding oncological outcomes.

\section{Materials and methods}

\section{Patients}

Institutional Review Board approval was obtained from the Sun Yat-sen Memorial Hospital (IRB Number: SYSEC-KY-KS-2020-045). Data were collected retrospectively from records of patients who underwent the M-MTIT or MTIT between January 2004 and December 2016. Tumors were classified according to the American Joint Committee on Cancer Staging System (1992). Our operative criteria were as follows: histologically confirmed invasive squamous cell carcinoma (stromal invasion $>1 \mathrm{~mm}$ ); clinical stage T2 $[\geq 4 \mathrm{~cm}]$ or T3; American Society of Anesthesiologists (ASA) score $\leq 3$. Patients who had clinically palpable lymph nodes or evidence of distant metastasis and patients with a history of previous vulvar and/or pelvic radiation therapy were excluded.

All vulvar cancer patients with clinical stage T2 [ $\geq 4 \mathrm{~cm}]$ or T3 disease, comprehensive preoperative evaluation was conducted by a multidisciplinary team, which consisted of two gynecologic oncologists, one radiologist, one urologist and one plastic surgeon $[7,8]$. For patients who were considered as poor candidates for surgery, concurrent chemoradiotherapy was recommended. All surgical procedures were performed by the same gynecologic oncology team. All patients received inguinal and femoral node dissection, which included superficial inguinal nodes and deep groin nodes. An equal extent of lymphadenectomy was employed in the MTIT and M-MTIT, and the great saphenous vein was preserved during the ILND procedure. The MTIT was performed as previously described [6]. Following the inguinofemoral lymphadenectomy, all patients received a modified radical vulvectomy. During the process of vulvectomy, the inner incision was deepened down to the inferior fascia of the urogenital diaphragm, while the outer incision was undermined laterally to separate the subcutaneous tissue of the skin bridge from the fat pad of the lateral thigh. Finally, the groin node-bearing fatty pad was removed together with the complete radical vulvectomy specimen. In case of a large defect of the vulva, plastic surgery reconstruction involving skinflaps was performed immediately by experienced plastic surgeons [9]. The M-MTIT differed in three respects from the original MTIT. First, an inguinal incision of 3-5 cm that was parallel to the inguinal ligament was used in the M-MTIT (Figure 1A); while a midline vertical inguinal incision of $8-10 \mathrm{~cm}$ was employed in the MTIT (Figure 1B). Second, radical excision of the vulvar tumor was performed with at least $1 \mathrm{~cm}$ clinically clear surgical margins in the M-MTIT, while the minimal macroscopic resection margin was $2 \mathrm{~cm}$ in the MTIT. Third, all patients treated with the M-MTIT received negative pressure wound therapy on groin incisions, while patients undergoing the MTIT received standard-of-care dressing. The duration of negative pressure therapy was five to seven days.

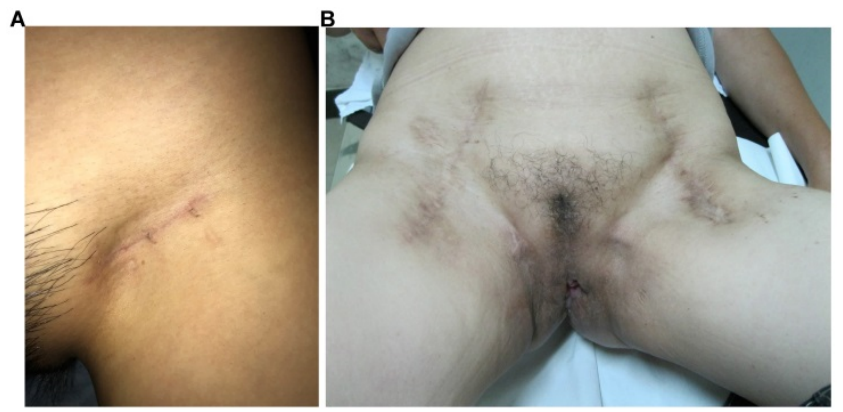

Figure 1. Appearance on the groin. (A) M-MTIT groin incision 8 months post-operative. (B) MTIT groin incision 12 months post-operative.

We used the same criteria as Rouzier for reporting postsurgical morbidity [10]. The adjuvant treatment following surgery was performed according to the National Comprehensive Cancer Network (NCCN) guidelines [1], and indications for adjuvant chemoradiotherapy on the groin and pelvis were as follows: close or positive surgical margins, lymphovascular space invasion (LVSI), lymph node metastasis and/or extracapsular lymph node involvement. Following initial treatment, patients underwent follow-up examinations every 3 months for the first 2 years, every 6 months for the next 3 years, and every year thereafter. Follow-up visits included an interview, palpation of the groins and a gynecological examination. Imaging studies, including computed tomography (CT), magnetic resonance imaging (MRI) and positron emission tomography (PET)/CT, were performed at the discretion of the treating physician. When tumor recurrence was suspected based on clinical findings or 
imaging studies, biopsies of the suspicious lesions were performed on a case-by-case basis.

\section{Statistical analysis}

We used STATA 12.0 (StataCorp, College Station, TX, USA) to perform all the statistical analyses. Baseline patient characteristics were compared between groups using Student's $t$ test or the Mann-Whitney $U$ test for continuous variables and the $\chi^{2}$ test or Fisher's exact test for categorical variables as appropriate. Multivariate logistic regression was used to determine independent risk factors for wound breakdown. All variables with significance at $P<0.30$ in the univariate analysis were considered candidates in the final model. This relatively liberal cutoff was chosen due to the small sample size that may have a risk of type II error with a lower cutoff. Survival curves were computed with the Kaplan-Meier method, and the significance of each survival difference was determined with the log-rank test. All statistical tests were two-sided, and a two-tailed $P$-value $<0.05$ was considered statistically significant.

\section{Results}

\section{Clinical and pathological variables}

Table 1 demonstrates the characteristics of the 57 patients who were included in the analysis. In our patient cohort, 28 (49.1\%) underwent the MTIT and 29 (50.9\%) underwent the M-MTIT. The majority $(73.7 \%)$ had $\mathrm{T} 2>4 \mathrm{~cm}$ disease, the median age at diagnosis was 58 years (range: $30-80$ years), and the median body mass index (BMI) was $22.1 \mathrm{~kg} / \mathrm{m}^{2}$ (range: $\left.15.2-28.4 \mathrm{~kg} / \mathrm{m}^{2}\right)$. Fourteen $(24.6 \%)$ patients had comorbidities that included hypertension, diabetes mellitus, heart disease, chronic obstructive pulmonary disease and systemic lupus erythematosus. No significant difference was noted between the two groups with respect to demographic characteristics and type of surgery.

\section{Treatment-related variables}

As deemed necessary by the primary surgeon to achieve adequate surgical margins, a colostomy, partial vaginectomy and partial urethral resection were performed in three $(5.2 \%)$, four $(7.0 \%)$ and nine $(15.8 \%)$ patients, respectively. Among the nine patients receiving urethral resection, three underwent a urethral resection of $1.0 \mathrm{~cm}$, two underwent a urethral resection of $1.5 \mathrm{~cm}$, and one underwent a urethral resection of $2 \mathrm{~cm}$. The length of the removed urethra was not recorded in the other three patients.

Operative data and histopathological findings are listed in Table 2. The median number of nodes removed was 12 (range: 8-17) and did not differ between the two groups. Following surgery, no patient experienced skin necrosis or urine incontinence. The median postoperative hospital stay was 30 days (range: 7-54 days) and was shorter in the M-MTIT group than in the MTIT group (25 days [range: 7-49 days] vs. 36 days [range: 24-54 days], respectively, $P<0.0001)$. Surgery related complications were noted in $24(42.1 \%)$ patients and 11 of them developed more than two complications. Surgical outcomes are summarized in Table 2 . Compared with patients in the MTIT group, fewer patients in the M-MTIT group had morbidities (24.1\% vs. $60.7 \%, P=0.005)$. Wound breakdown was observed in 13 patients (22.8\%) and was less often observed in patients receiving the M-MTIT than in those receiving the MTIT $(10.3 \%$ vs. $35.7 \%, P=0.022)$. The incidence of other major complications, including lymphedema $(34.5 \%$ vs. $42.9 \%, P=0.516)$, wound infection $(3.5 \%$ vs. $17.9 \%, P=0.076)$ and cellulitis (3.5\% vs. $10.7 \%, P=0.283$ ), was lower among patients undergoing the M-MTIT; however, the differences did not reach statistical significance.

Table 1. Patient characteristics

\begin{tabular}{|c|c|c|c|}
\hline Variables & $\operatorname{MTIT}(n=28)$ & M-MTIT $(n=29)$ & $\begin{array}{l}P \\
\text { value }\end{array}$ \\
\hline Age (years), median (range) & $57.5(30-75)$ & $58.0(32-80)$ & 0.367 \\
\hline BMI $\left(\mathrm{kg} / \mathrm{m}^{2}\right)$, median (range) & $22.4(15.2-28.4)$ & $21.4(16.7-26.2)$ & 0.515 \\
\hline \multicolumn{4}{|l|}{ Smoking, n (\%) } \\
\hline Never & $24(85.7)$ & $26(89.7)$ & 0.158 \\
\hline Former & $4(14.3)$ & $1(6.9)$ & \\
\hline Current & $0(0)$ & $2(3.5)$ & \\
\hline \multicolumn{4}{|l|}{ HPV infection, $\mathrm{n}(\%)$} \\
\hline No & $0(0)$ & $1(3.5)$ & 0.861 \\
\hline High risk & $11(39.3)$ & $14(48.3)$ & \\
\hline Low risk & $6(21.4)$ & $6(26.7)$ & \\
\hline Unreported & $5(17.9)$ & $3(10.3)$ & \\
\hline Comorbidities & $6(21.4)$ & $5(17.2)$ & \\
\hline $\begin{array}{l}\text { Diameter of primary tumor }(\mathrm{cm}) \text {, } \\
\text { median (range) }\end{array}$ & $5.5(4-8)$ & $5.5(4-8)$ & 0.493 \\
\hline \multicolumn{4}{|l|}{ Grade of primary tumor, $\mathrm{n}(\%)$} \\
\hline G1-2 & $20(71.4)$ & $20(69.0)$ & 0.839 \\
\hline G3 & $8(28.6)$ & $9(31.0)$ & \\
\hline \multicolumn{4}{|c|}{ Clinical stage of the primary tumor, $n(\%)$} \\
\hline $\mathrm{T} 2>4 \mathrm{~cm}$ & $20(71.4)$ & $22(75.9)$ & 0.704 \\
\hline $\mathrm{T} 3$ & $8(28.6)$ & $7(24.1)$ & \\
\hline Patients with comorbidities, $\mathrm{n}(\%)$ & $6(21.4)$ & $8(27.6)$ & 0.589 \\
\hline Hypertension & $2(7.1)$ & $3(10.3)$ & \\
\hline Diabetes mellitus & $1(3.6)$ & $2(6.9)$ & \\
\hline Heart disease & $2(7.1)$ & $2(6.9)$ & \\
\hline COPD & $1(3.6)$ & $0(0)$ & \\
\hline SLE & $0(0)$ & $1(3.5)$ & \\
\hline
\end{tabular}

Because wound breakdown was the most common short-term complication of the entire cohort, we conducted regression analysis to detect independent predictors associated with it. The results are listed in Table 3. On the univariate analysis, only 
the inguinal incision type was significantly (odds ratio $[\mathrm{OR}]=0.21,95 \%$ confidence interval $[\mathrm{CI}][0.05,0.86], P$ $=0.030$ ) associated with the risk of wound breakdown. On the multivariate analysis, which incorporated all variables with $P<0.30$ on the univariate analysis, the type of inguinal incision remained independently associated with the risk of wound breakdown $(\mathrm{OR}=0.18,95 \%$ CI $[0.04,0.83], P=$ $0.028)$.

Table 2. Surgical characteristics and incidence of post-operative complications

\begin{tabular}{|c|c|c|c|}
\hline Variables & MTIT $(n=28)$ & $\begin{array}{l}\text { M-MTIT } \\
(\mathrm{n}=29)\end{array}$ & $P$ value \\
\hline Operative time (min), median (range) & $141(70-265)$ & $150(70-295)$ & 0.648 \\
\hline Estimated blood loss (ml), median (range) & $50(10-300)$ & $60(10-200)$ & 0.550 \\
\hline Colostomy, n (\%) & $2(7.1)$ & $1(3.5)$ & 0.975 \\
\hline Vulvovaginal reconstruction, $\mathrm{n}(\%)$ & $6(21.4)$ & $6(20.7)$ & 0.945 \\
\hline Partial vaginectomy, $\mathrm{n}(\%)$ & $2(7.1)$ & $2(6.9)$ & 0.630 \\
\hline Partial urethral resection, $\mathrm{n}(\%)$ & $4(14.3)$ & $5(17.2)$ & 0.954 \\
\hline $\begin{array}{l}\text { No. of lymph nodes removed, median } \\
\text { (range) }\end{array}$ & $12(9-16)$ & $13(8-17)$ & 0.270 \\
\hline Blood transfusion, $\mathrm{n}(\%)$ & $4(14.3)$ & $1(3.5)$ & 0.148 \\
\hline Positive margins, $\mathrm{n}(\%)$ & $1(3.6)$ & $1(3.5)$ & 0.980 \\
\hline Positive nodes, n (\%) & $8(28.6)$ & $9(31.0)$ & 0.839 \\
\hline LVSI, n (\%) & $6(21.4)$ & $4(13.8)$ & 0.449 \\
\hline $\begin{array}{l}\text { Postoperative concurrent } \\
\text { chemoradiotherapy, n (\%) }\end{array}$ & $9(32.1)$ & $9(31.0)$ & 0.928 \\
\hline Lymphedema, n (\%) & $12(42.9)$ & $10(34.5)$ & 0.516 \\
\hline Wound breakdown, n (\%) & $10(35.7)$ & $3(10.3)$ & 0.022 \\
\hline vulvar wound & 0 & 0 & \\
\hline groin wound & $10(35.7)$ & $3(10.3)$ & 0.022 \\
\hline Wound infection, n (\%) & $5(17.9)$ & $1(3.5)$ & 0.076 \\
\hline vulvar wound & $3(10.7)$ & $1(3.5)$ & 0.579 \\
\hline groin wound & $2(7.1)$ & 0 & 0.143 \\
\hline Cellulitis, n (\%) & $3(10.7)$ & $1(3.5)$ & 0.283 \\
\hline DVT, $\mathrm{n}(\%)$ & $1(3.6)$ & $1(3.5)$ & 0.980 \\
\hline Urine incontinence, $\mathrm{n}(\%)$ & $0(0)$ & $0(0)$ & \\
\hline $\begin{array}{l}\text { Postoperative hospital stay (days), median } \\
\text { (range) }\end{array}$ & $36(24-54)$ & $25(7-49)$ & $<0.0001$ \\
\hline
\end{tabular}

Table 3. Univariate and multivariate analysis of factors associated with wound breakdown

\begin{tabular}{|c|c|c|c|c|}
\hline & \multicolumn{2}{|c|}{ Univariate analysis } & \multicolumn{2}{|c|}{ Multivariate analysis } \\
\hline & OR 95\% CI & $P$ value & OR 95\% CI & $P$ value \\
\hline $\begin{array}{l}\text { Types of triple incision } \\
\text { (M-MTIT vs. MTIT) }\end{array}$ & $0.21 \quad 0.05-0.86$ & 0.030 & $0.18 \quad 0.04-0.83$ & 0.028 \\
\hline Age (years) & $0.990 .94-1.04$ & 0.576 & & \\
\hline BMI $\left(\mathrm{kg} / \mathrm{m}^{2}\right)$ & $1.040 .83-1.29$ & 0.741 & & \\
\hline Operative time (min) & $1.00 \quad 0.99-1.02$ & 0.422 & & \\
\hline Estimated blood loss (ml) & $1.011 .00-1.02$ & 0.063 & $1.01 \quad 1.00-1.02$ & 0.072 \\
\hline Comorbidity (yes vs. no) & $1.510 .38-5.96$ & 0.556 & & \\
\hline Stage (T3 vs. T2>4cm) & $2.130 .57-7.96$ & 0.263 & $1.450 .30-7.01$ & 0.641 \\
\hline Diameter $(\mathrm{cm})$ & $1.38 \quad 0.75-2.51$ & 0.297 & $1.230 .61-2.49$ & 0.568 \\
\hline
\end{tabular}

\section{Survival analysis}

The median follow-up time was 33 months (range: 13-55 months) for the entire cohort, and no patient was lost to follow-up. As shown in Table 4, four patients in the MTIT group (6, 21, 22 and 28 months after primary surgery) and two patients in the M-MTIT group (20 and 23 months after primary surgery) experienced tumor recurrence. Of the six patients who developed recurrence, skin abridge failure was noted in three, and all of the lesions were successfully salvaged with a local re-resection. Distant recurrence was documented in three patients who underwent tumor-targeted radiotherapy and systemic chemotherapy but ultimately died of disease. Eight deaths were recorded, five $(62.5 \%)$ of which were a result of medical comorbidities, including pulmonary infection, respiratory failure, heart failure, stroke and renal failure. Figure $\mathbf{2}$ demonstrates the survival curves for recurrence-free survival (RFS) and overall survival (OS). The estimated 1-, 2-, and 3-year RFS rates for patients receiving the MTIT were $92.9 \%$, $89.1 \%$, and $84.5 \%$, respectively, compared with $100 \%$, $88.7 \%$, and $88.7 \%$, respectively, for those receiving the M-MTIT. The estimated 1-, 2-, and 3-year OS rates for patients receiving the MTIT were $100 \%, 100 \%$, and $85.2 \%$, respectively, compared with $100 \%, 96.0 \%$, and $96.0 \%$, respectively, for those receiving the M-MTIT. RFS (unadjusted hazard ratio [HR] $=0.69,95 \% \mathrm{CI}$ $[0.13,3.78]$; log-rank $P=0.667)$ was similar in the two groups, as was OS (unadjusted $\mathrm{HR}=1.76,95 \% \mathrm{CI}$ $[0.38,8.11]$; log-rank $P=0.466)$.
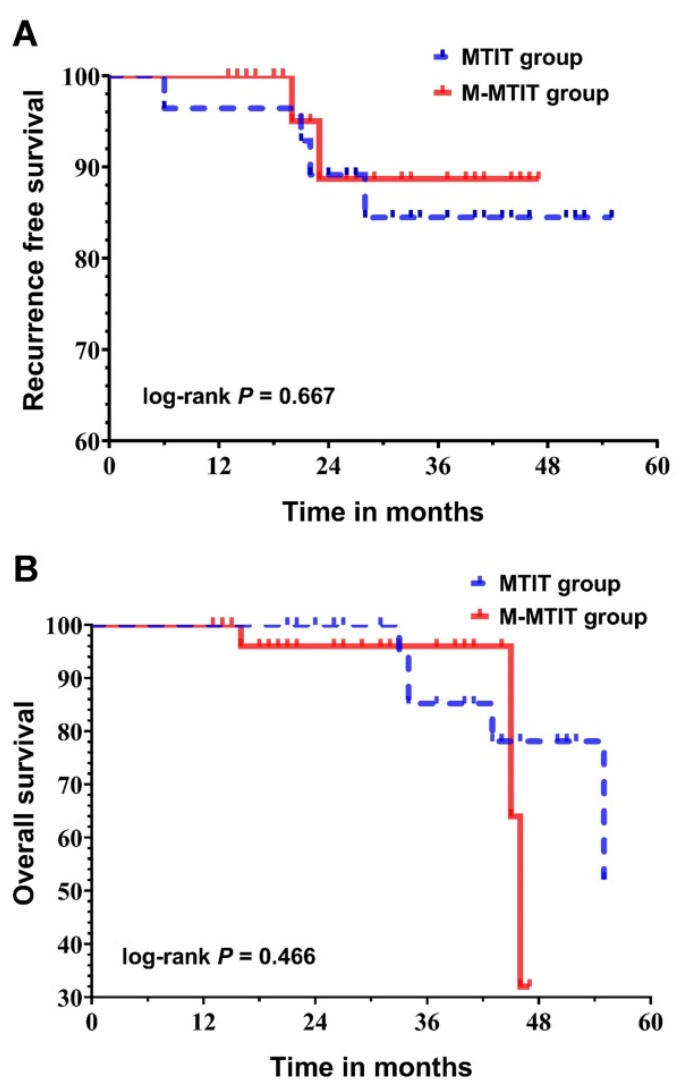

Figure 2. Kaplan-Meier curves of recurrence-free survival (A) and overall survival (B). 
Table 4. Pattern of recurrence and deaths by treatment arm

\begin{tabular}{lll}
\hline & MTIT (n=28) & M-MTIT (n=29) \\
\hline Time of follow-up, median (range) (months) & $41(21-55)$ & $27(13-47)$ \\
No. of patients with recurrence & 4 & 2 \\
Site of recurrence & & \\
Skin abridge & 2 & 1 \\
Lung & 1 & 1 \\
Bone & 1 & 0 \\
No. of death & 5 & 3 \\
Cause of death & & \\
Tumor recurrence & 2 & 1 \\
Non-cancer-related causes & 3 & 2 \\
\hline
\end{tabular}

MTIT, modified triple incision technique; M-MTIT, modified MTIT.

\section{Discussion}

For vulvar cancer patients with locally advanced disease (clinical stage T2 $[\geq 4 \mathrm{~cm}]$ or T3), en bloc radical vulvectomy with bilateral ILND remains the optimal therapeutic option [1-3]. The rate of complications following this treatment is significant, occurring in up to $85 \%$ of patients [11]. To reduce surgery-related morbidity, several modified surgical methods have been proposed. Although the MTIT is less morbid than the traditional en bloc approach, a considerable portion of patients still suffer from postoperative complications [6]. Thus, we proposed the M-MTIT, which can be considered a modification of the MTIT, and we made comparisons between the M-MTIT and MTIT. Our data suggest that the M-MTIT is superior to the MTIT.

In the present study, wound breakdown was the most common postsurgical complication with an incidence of $22.8 \%$, which is consistent with previous reports. However, patients in the M-MTIT group had a significantly lower incidence of wound breakdown than patients in the MTIT group $(10.3 \%$ vs. $35.7 \%$, $P=0.022)$. This finding was further strengthened by the regression analysis, where the M-MTIT was identified to be independently associated with a decreased risk of wound breakdown $(\mathrm{OR}=0.18,95 \%$ CI [0.04, 0.83], $P=0.028$ ). Among previous studies regarding the triple incision technique, Rouzier's retrospective study examined the largest sample size to date: 194 vulvar cancer patients [10]. The authors found that the incidence of wound breakdown is influenced by the extent of lymphadenectomy $[12,13]$, and the highest incidence $(38.3 \%)$ was documented in patients receiving ILND via the traditional triple incision technique. The extent of ILND and criteria to define complications in the current study were the same as those described by Rouzier et al. [10]. However, we found that only $10.3 \%$ of the patients in the M-MTIT group experienced wound breakdown. By comparing the M-MTIT with the MTIT and Rouzier's data [10], we believe that the M-MTIT can reduce the risk of wound breakdown. This benefit may be attributed to the small inguinal incision used in the M-MTIT and the use of negative pressure wound therapy [14-16].

Other surgery-related complications, including lymphedema $(34.5 \%$ vs. $42.9 \%, P=0.516)$, wound infection $(3.5 \%$ vs. $17.9 \%, P=0.076)$ and cellulitis $(3.5 \%$ vs. 10.7, $P=0.283$ ), were less likely to occur in patients treated with the M-MTIT than in patients treated with the MTIT; however, the differences did not reach statistical significance. Despite this finding, compared with the reported incidence of lymphedema $(47 \%)$ and cellulitis (29.1\%) by Rouzier [10], the M-MTIT is less morbid. The development of and cellulitis is related to the extent of lymphadenectomy [11, 17], and 10 nodes from a bilateral dissection can be considered radical for vulvar cancer patients $[18,19]$. In the present study, the median numbers of resected nodes in the M-MTIT and MTIT groups were 13 and 12 , respectively $(P=0.270)$. Therefore, the lower morbidity associated with the M-MTIT does not compromise the radical tumor clearance of lymphadenectomy. The great saphenous is an important route of lower extremity lymphovascular circulation. Preservation of the great saphenous during lymphadenectomy has been reported as an effective method to reduce the risk of lymphedema and infection [10, 20], which could explain the differences between our data and others.

Locally advanced vulvar cancer is associated with a significant risk of local recurrence, and the tumor margin status has been validated as a significant prognostic factor $[1,2,21]$. To decrease the risk of local recurrence, most guidelines recommend a histological tumor-free margin of at least $8 \mathrm{~mm}[1,3$, 22-24], which corresponds to a surgical margin of 1-2 $\mathrm{cm}$ [25]. There is evidence showing $0 \%$ recurrence rates for $>8 \mathrm{~mm}$ margins and $47 \%$ when the margins are $\leq 8 \mathrm{~mm}[3,25,26]$. However, a recent multicenter cohort study by the Francogyn Study Group, where 112 vulvar cancer patients who received treatment in four French university hospitals were included, did not find that tumor-free margin distance had survival influence [26]. In Micheletti's study [27] which included 114 patients, the minimum histological margin distance that conferred long-term oncological safety was $5 \mathrm{~mm}$. Of note, this study reviewed data from 1981 to 2014, during which time the management of vulvar cancer has changed considerably. The theory of ontogenetic cancer fields could be a plausible explanation for the inconsistent findings in previous studies [28, 29]. Collectively, in light of current evidence, there is no convincing data supporting that pathologic margins $<8 \mathrm{~mm}$ is safe. The width of the surgical margin $(1 \mathrm{~cm}$ vs. $2 \mathrm{~cm})$ was relatively narrow in the M-MTIT group; however, this 
did not result in an increased incidence of microscopic positive margins $(3.5 \%$ vs. $3.6 \%, P=0.980)$. Based on our findings and available evidence, we believe that a macroscopic tumor-free margin should be at least 1 cm [1-3, 22-24].

The median follow-up time of our study was 33 months, which allowed us to observe most cases of recurrence [30]. We did not find any survival difference between the two groups. Additionally, survival data in the current study were comparable to those in other studies [10, 31]. These findings suggest that oncological safety can be ensured with the M-MTIT.

Of note, patients enrolled in this study, with the median age of 58 years, were younger than in white patient populations in previous studies [32, 33], but the median age was consistent with that reported in similar studies involving Chinese patients [34, 35]. Additionally, a severe reduction of OS was noted after 48 months of surgery. Some of our patients were older and some had serious complications at diagnosis, which may explain why mortality increased significantly over time. Furthermore, we acknowledge that the present study had some limitations. First, this study is limited by biases related to its retrospective design. In addition, vulvar cancer is a rare disease. Although we pooled 12 years of data, the sample size of this work is only moderate for survival analyses, and it is difficult to identify more complicationrelated risk factors. Additionally, many Chinese patients favor a longer hospital stay because they believe it assures a better recovery [6]. Thus, the length of hospital stay may not serve as an objective factor. Third, since patients in the M-MTIT group received negative pressure therapy following surgery, there were differences in wound care between the groups. This could have resulted in biased results when we assessed the wound complications. Finally, although the two technologies differ in three main ways that include the width of the surgical margin, surgical incisions and the utility of negative pressure wound treatment, the specific influence of each of these variables on the final outcomes could not be clarified.

In summary, our study suggests that the M-MTIT correlates with lower morbidity rates than the MTIT and other traditional triple incision techniques and does not compromise oncological safety. We believe that the M-MTIT should be considered a safe and feasible option for vulvar cancer patients with locally advanced disease. Further investigations are merited to validate our conclusions.

\section{Acknowledgments}

\section{Ethics approval}

The study complied with the Declaration of Helsinki and was approved by the Medical Ethics Committee of Sun Yat-sen Memorial Hospital, Sun Yat-sen University. Our research used existing data and records, which had been recorded in a manner that all the patients cannot be identified, directly or through identifiers linked to the patients.

\section{Financial disclaimer}

This research was funded by China Scholarship Council (grant number 201906385061).

\section{Competing Interests}

The authors have declared that no competing interest exists.

\section{References}

1. Koh WJ, Greer BE, Abu-Rustum NR, Campos SM, Cho KR, Chon HS, et al. Vulvar Cancer, Version 1.2017, NCCN Clinical Practice Guidelines in Oncology. J Natl Compr Canc Netw. 2017;15(1):92-120.

2. Oonk MHM, Planchamp F, Baldwin P, Bidzinski M, Brannstrom M, Landoni F, et al. European Society of Gynaecological Oncology Guidelines for the Management of Patients With Vulvar Cancer. Int J Gynecol Cancer. 2017;27(4):832-7.

3. Rogers LJ, Cuello MA. Cancer of the vulva. Int J Gynaecol Obstet. 2018;143 Suppl 2:4-13.

4. Te Grootenhuis NC, van der Zee AG, van Doorn HC, van der Velden J, Vergote I, Zanagnolo V, et al. Sentinel nodes in vulvar cancer: Long-term follow-up of the GROningen INternational Study on Sentinel nodes in Vulvar cancer (GROINSS-V) I. Gynecol Oncol. 2016;140(1):8-14.

5. Van der Zee AG, Oonk MH, De Hullu JA, Ansink AC, Vergote I, Verheijen $\mathrm{RH}$, et al. Sentinel node dissection is safe in the treatment of early-stage vulvar cancer. J Clin Oncol. 2008;26(6):884-9.

6. Li J, Zhou H, Wang LJ, Lu XM, Rao QX, Lu HW, et al. A modified triple incision technique for women with locally advanced vulvar cancer: a description of the technique and outcomes. Eur J Obstet Gynecol Reprod Biol. 2012;164(2):185-90.

7. Garganese G, Collarino A, Fragomeni SM, Rufini V, Perotti G, Gentileschi S, et al. Groin sentinel node biopsy and (18)F-FDG PET/CT-supported preoperative lymph node assessment in $\mathrm{cN0}$ patients with vulvar cancer currently unfit for minimally invasive inguinal surgery: The GroSNaPET study. Eur J Surg Oncol. 2017;43(9):1776-83.

8. Garganese G, Fragomeni SM, Pasciuto T, Leombroni M, Moro F, Evangelista MT, et al. Ultrasound morphometric and cytologic preoperative assessment of inguinal lymph-node status in women with vulvar cancer: MorphoNode study. Ultrasound Obstet Gynecol. 2020;55(3):401-10.

9. Gentileschi S, Servillo M, Garganese G, Fragomeni S, De Bonis F, Scambia G, et al. Surgical therapy of vulvar cancer: how to choose the correct reconstruction? J Gynecol Oncol. 2016;27(6):e60.

10. Rouzier R, Haddad B, Dubernard G, Dubois P, Paniel BJ. Inguinofemoral dissection for carcinoma of the vulva: effect of modifications of extent and technique on morbidity and survival. J Am Coll Surg. 2003;196(3):442-50.

11. Wills A, Obermair A. A review of complications associated with the surgical treatment of vulvar cancer. Gynecol Oncol. 2013;131(2):467-79.

12. Micheletti L, Preti M. Surgery of the vulva in vulvar cancer. Best Pract Res Clin Obstet Gynaecol. 2014;28(7):1074-87.

13. Dellinger TH, Hakim AA, Lee SJ, Wakabayashi MT, Morgan RJ, Han ES. Surgical Management of Vulvar Cancer. J Natl Compr Canc Netw. 2017;15(1):121-8.

14. Pleger SP, Nink N, Elzien M, Kunold A, Koshty A, Boning A. Reduction of groin wound complications in vascular surgery patients using closed incision negative pressure therapy (ciNPT): a prospective, randomised, singleinstitution study. Int Wound J. 2018;15(1):75-83.

15. Wahab NAA, Saadeh FA, Wong A, Gleeson N. Negative pressure wound treatment (NPWT) in vulva and groin wounds in gynaecologic oncology. Eur J Gynaecol Oncol. 2016;37(5):632-7.

16. Crosbie EJ, Slade RJ, Ahmed AS. The management of vulval cancer. Cancer Treat Rev. 2009;35(7):533-9.

17. Gentileschi S, Servillo M, Garganese G, Fragomeni S, De Bonis F, Cina A, et al. The lymphatic superficial circumflex iliac vessels deep branch perforator flap: 
A new preventive approach to lower limb lymphedema after groin dissection-preliminary evidence. Microsurgery. 2017;37(6):564-73.

18. Le T, Elsugi R, Hopkins L, Faught W, Fung-Kee-Fung M. The definition of optimal inguinal femoral nodal dissection in the management of vulva squamous cell carcinoma. Ann Surg Oncol. 2007;14(7):2128-32.

19. Rouzier R, Haddad B, Atallah D, Dubois P, Paniel BJ. Surgery for vulvar cancer. Clin Obstet Gynecol. 2005;48(4):869-78.

20. Zhang $X$, Sheng X, Niu J, Li H, Li D, Tang L, et al. Sparing of saphenous vein during inguinal lymphadenectomy for vulval malignancies. Gynecol Oncol. 2007;105(3):722-6.

21. Te Grootenhuis NC, Pouwer AW, de Bock GH, Hollema H, Bulten J, van der Zee AGJ, et al.. Margin status revisited in vulvar squamous cell carcinoma. Gynecol Oncol. 2019;154(2):266-75.

22. Morrison I, Baldwin P, Buckley L, Cogswell L, Edey K, Faruqi A, et al. British Gynaecological Cancer Society (BGCS) vulval cancer guidelines: Recommendations for practice. Eur J Obstet Gynecol Reprod Biol. 2020.

23. Obstetricians RCo, Gynaecologists. Guidelines for the diagnosis and management of vulval carcinoma. RCOG, London. 2014.

24. Saito T, Tabata T, Ikushima H, Yanai H, Tashiro H, Niikura H, et al. Japan Society of Gynecologic Oncology guidelines 2015 for the treatment of vulvar cancer and vaginal cancer. Int J Clin Oncol. 2018;23(2):201-34.

25. Kortekaas KE, Van de Vijver KK, van Poelgeest MIE, Gilks CB, Smit V, Arif S, et al. Practical Guidance for Measuring and Reporting Surgical Margins in Vulvar Cancer. Int J Gynecol Pathol. 2019.

26. Raimond E, Delorme C, Ouldamer L, Carcopino X, Bendifallah S, Touboul C, et al. Surgical treatment of vulvar cancer: Impact of tumor-free margin distance on recurrence and survival. A multicentre cohort analysis from the francogyn study group. Eur J Surg Oncol. 2019;45(11):2109-14.

27. Micheletti L, Preti M, Cintolesi V, Corvetto E, Privitera S, Palmese E, et al. Prognostic impact of reduced tumor-free margin distance on long-term survival in FIGO stage IB/II vulvar squamous cell carcinoma. J Gynecol Oncol. 2018;29(5):e61.

28. Hockel M, Schmidt K, Bornmann K, Horn LC, Dornhofer N. Vulvar field resection: novel approach to the surgical treatment of vulvar cancer based on ontogenetic anatomy. Gynecol Oncol. 2010;119(1):106-13.

29. Hockel M, Trott S, Dornhofer N, Horn LC, Hentschel B, Wolf B. Vulvar field resection based on ontogenetic cancer field theory for surgical treatment of vulvar carcinoma: a single-centre, single-group, prospective trial. Lancet Oncol. 2018;19(4):537-48.

30. Gonzalez Bosquet J, Magrina JF, Gaffey TA, Hernandez JL, Webb MJ, Cliby WA, et al. Long-term survival and disease recurrence in patients with primary squamous cell carcinoma of the vulva. Gynecol Oncol. 2005;97(3):828-33.

31. Gaulin NB, Lesnock JL, Tian C, Osei-Bonsu K, Jacobs A, Richard SD, et al. Survival disparities in vulvar cancer patients in Commission on Cancer(R)-accredited facilities. Gynecol Oncol. 2019.

32. Ghebre RG, Posthuma R, Vogel RI, Geller MA, Carson LF. Effect of age and comorbidity on the treatment and survival of older patients with vulvar cancer. Gynecol Oncol. 2011;121(3):595-9.

33. Hami LT, Lampe B, Mallmann P, Forner DM. The Impact of Age on the Prognosis of Vulvar Cancer. Oncol Res Treat. 2018;41(9):520-4.

34. Zhang M, Chen L, Zhang X, Ding J, Hua K. A Comparative Study of Video Endoscopic Inguinal Lymphadenectomy and Conventional Open Inguinal Lymphadenectomy for Treating Vulvar Cancer. Int J Gynecol Cancer. 2017;27(9):1983-9.

35. Li J, Cai Y, Ke G, Xiang L, Wang L, Yang W, et al. Validation of the new FIGO staging system (2009) for vulvar cancer in the Chinese population. Gynecol Oncol. 2015;137(2):274-9. 